Volume 121, Number 6

\title{
NORWOOD OPERATION FOR LEFT ISOMERIC HEART WITH AORTIC ATRESIA: EVALUATION WITH THREE-DIMENSIONAL COMPUTED TOMOGRAPHY
}

\author{
Masaaki Yamagishi, MD, ${ }^{\text {a }}$ Katsuji Fujiwara, MD, ${ }^{\text {a }}$ Yoshiaki Yamada, MD, ${ }^{\text {a }}$ Masahiro Yoshida, MD, ${ }^{a}$ Keisuke Shuntoh, MD, \\ Isao Shiraishi, MD, ${ }^{\mathrm{b}}$ Takashi Hayano, MD, ${ }^{\mathrm{b}}$ Toshiyuki Itoi, MD, ${ }^{\mathrm{b}}$ Kenji Hamaoka, MD, ${ }^{\mathrm{b}}$ and Nobuo Kitamura, MD, ${ }^{\mathrm{a}}$ \\ Kyoto, Japan
}

From the Departments of Pediatric Cardiovascular Surgery a and Pediatrics, ${ }^{\text {b }}$ Children's Research Hospital, Kyoto Prefectural University of Medicine, Kyoto, Japan.

J Thorac Cardiovasc Surg 2001;121:1205-7

Copyright (C) 2001 by The American Association for Thoracic Surgery

$0022-5223 / 2001 \$ 35.00+0 \quad \mathbf{1 2 / 5 4 / 1 1 2 4 6 1}$

doi:10.1067/mtc.2001.112461
Visceroatrial heterotaxia frequently involves cardiac anomalies. ${ }^{1}$ We report the case histories of 2 neonates with the rare combination of left isomerism and aortic atresia who underwent a successful Norwood operation.

Clinical summaries

PATIENT 1. A female neonate weighing $3020 \mathrm{~g}$ was referred to us with respiratory distress. Echocardiography showed a common atrium, dominant right ventricle with posterior rudimenta-
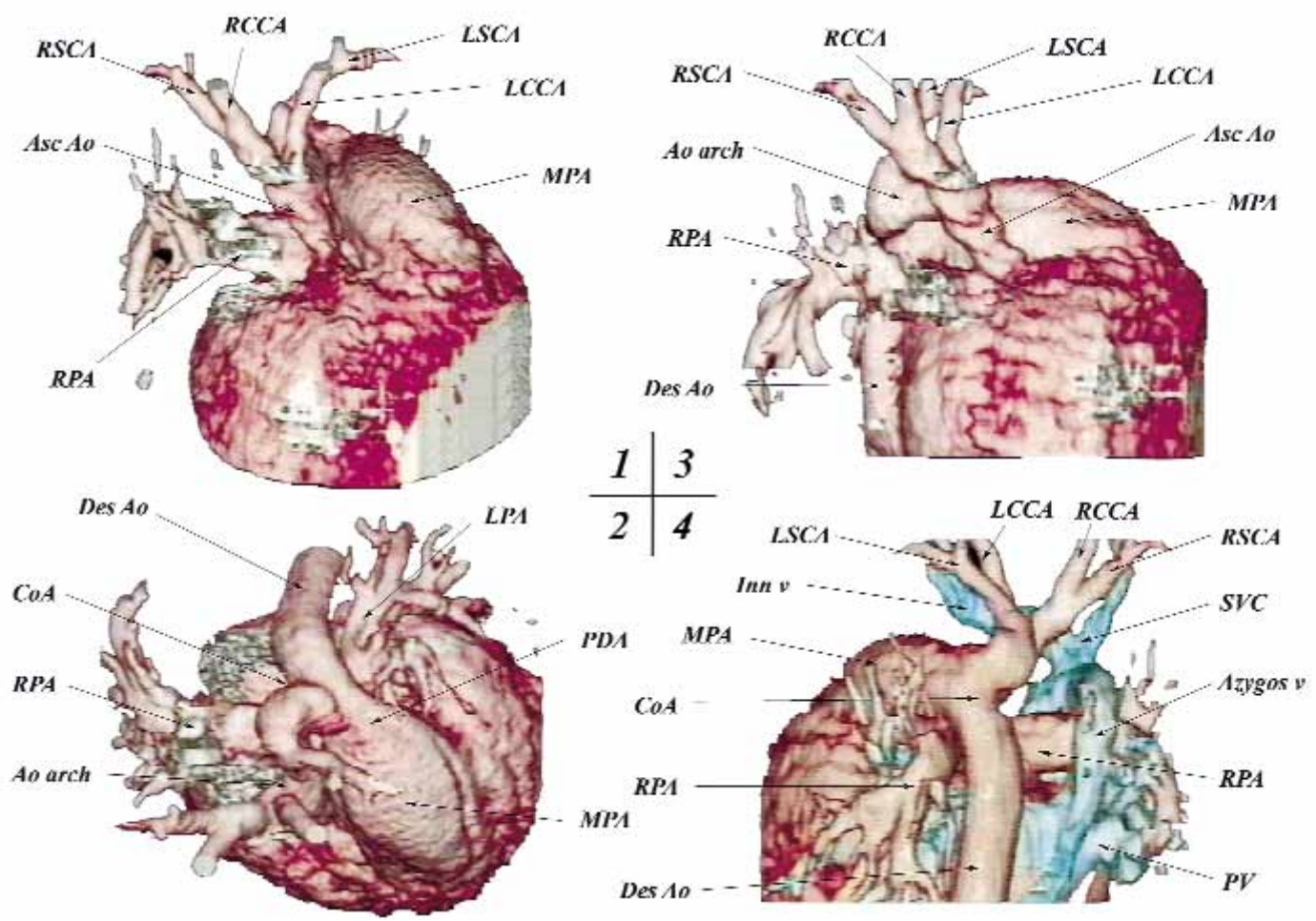

Fig 1. Preoperative helical computed tomography: case 1. 1, Antero-upper view; 2, upper view; 3, right view; 4, left posterior view. Images of systemic and pulmonary veins are deleted in 1, 2, and 3. Ao arch, Aortic arch; Asc $A o$, ascending aorta; Azygos v, azygos vein; CoA, coarctation of the aorta; Des Ao, descending aorta; Inn $v$, innominate vein; $L C C A$, left common carotid artery; $L P A$, left pulmonary artery; $L S C A$, left subclavian artery; $M P A$, main pulmonary artery; $P V$, pulmonary vein; $R C C A$, right common carotid artery; $R P A$, right pulmonary artery; $R S C A$, right subclavian artery. 


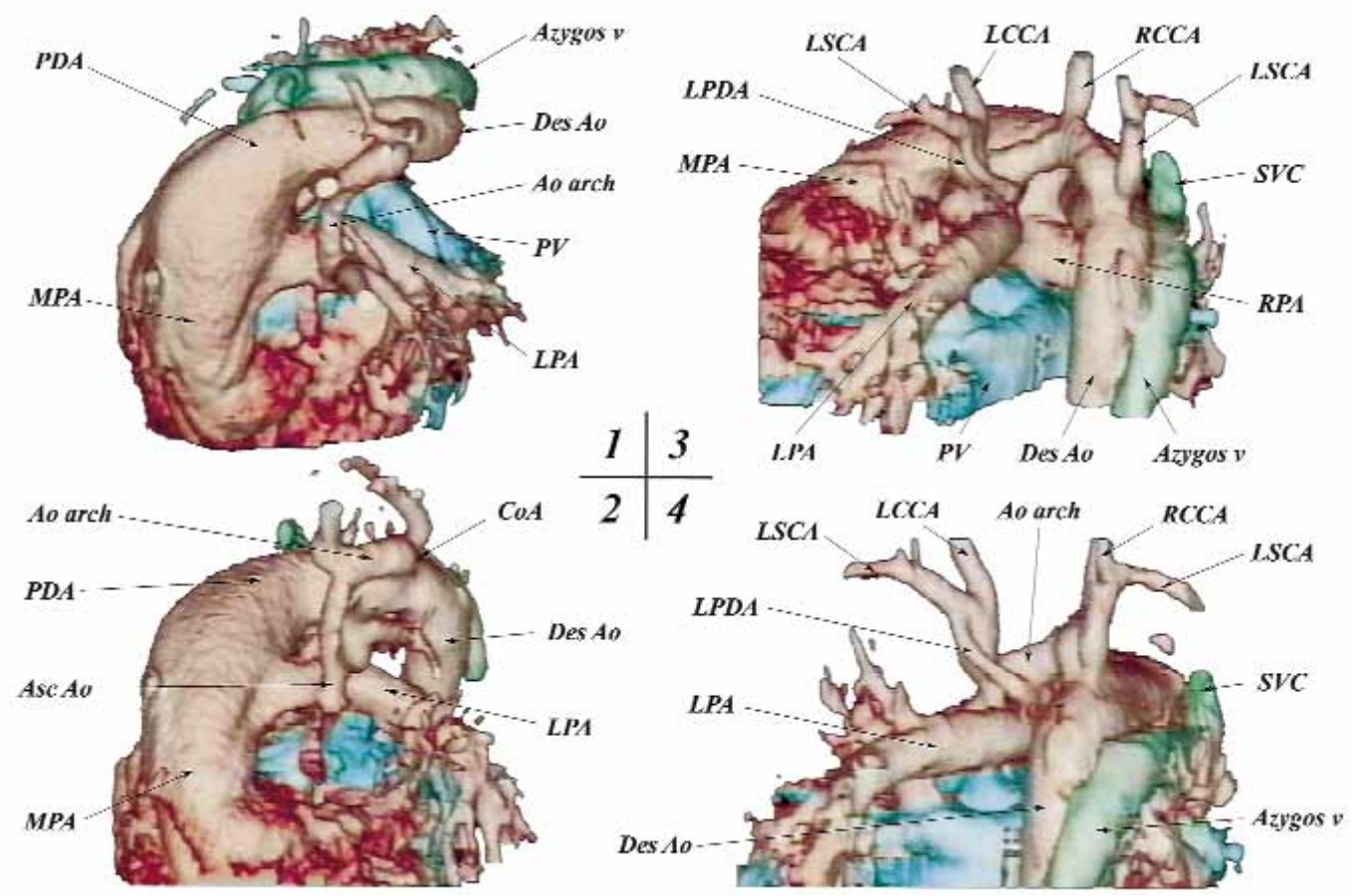

Fig 2. Preoperative helical computed tomography: case 2. 1, Upper view; 2, left upper view; 3, left posterior view; 4, right posterior view. Ao arch, Aortic arch; Asc Ao, ascending aorta; Azygos v, azygos vein; CoA, coarctation of the aorta; Des Ao, descending aorta; Inn v, innominate vein; $L C C A$, left common carotid artery; $L P A$, left pulmonary artery; $L P D A$, left persistent ductus arteriosus; $L S C A$, left subclavian artery; MPA, main pulmonary artery; $P V$, pulmonary vein; $R C C A$, right common carotid artery; $R P A$, right pulmonary artery; $R S C A$, right subclavian artery.

ry left ventricle, common atrioventricular valve, aortic atresia, and patent ductus arteriosus (PDA). The helical computed tomographic (CT) angiography (X Vigor Laudator; Toshiba Corporation, Tokyo, Japan) was safely performed under a shortperiod respiratory hold (approximately 20 seconds) because the patient had been already intubated. Three-dimensional (3-D) differential color images ${ }^{2}$ were reconstructed by using an image analyzer (X Tension, Toshiba). Video movies of rotating 3-D helical CT images were also provided for the better recognition of the anomalies. The 3-D helical CT image showed hypoplasia of the ascending aorta and aortic arch, coarctation of the aorta, PDA, deficiency of the inferior vena cava (IVC), and dilated azygos vein draining to the superior vena cava (SVC; Fig 1).

Surgical repair was performed at 12 days of age. Both atrial appendages were morphologically left appendages. A 3.5$\mathrm{mm}$ expanded polytetrafluoroethylene graft ${ }^{*}$ was anastomosed with the brachiocephalic artery. The right upper part of the body and ascending aorta were continuously perfused throughout the repair. The lower half of the body was perfused through a flexible arterial cannula inserted into the descending aorta through the PDA. The SVC and hepatic vein were also cannulated. Accurate orientation of incised line at

*Gore-Tex; registered trade name of W. L. Gore \& Associates, Inc, Flagstaff, Ariz. the great arteries was verified by reference to the 3-D helical CT images on the assumption of the reconstructed neoaorta. After institution of moderate hypothermic cardiopulmonary bypass, the main pulmonary artery was transected at its bifurcation. The pulmonary artery bifurcation was filled with a fresh autologous pericardium. Circulatory arrest of the lower part and left upper part of the body was initiated after clamping the proximal aortic arch, the left carotid artery, and the left subclavian artery. Ductal tissue was totally removed. Lesser curvature of the aortic arch was incised just before the origin of the brachiocephalic artery. The neoaortic arch was reconstructed by means of direct anastomosis among the proximal pulmonary stump, aortic arch, and descending aorta without use of prosthetic material. Atrial septectomy was unnecessary because of the presence of a common atrium. The opposite end of an expanded polytetrafluoroethylene tube was anastomosed to the central pulmonary artery. All procedures were performed with the heart beating. Placement of a second-stage bilateral bidirectional cavopulmonary shunt was performed 6 months after the Norwood operation.

PATIENT 2. A male neonate weighing $3100 \mathrm{~g}$ was referred to our hospital for surgical repair. Echocardiography disclosed a common atrium, dominant right ventricle with posterior rudimentary left ventricle, common atrioventricular valve, severe atrioventricular valve regurgitation, aortic atresia, right aortic 
arch, and PDA. Helical CT showed an anterior main pulmonary artery, posterior hypoplastic ascending aorta, hypoplasia of a right-sided aortic arch, coarctation of the aorta, bilateral PDA, right-sided descending aorta, stenosis at the origin of the right subclavian artery, deficiency of the IVC, bilateral SVC, and drainage of the azygos vein to the right SVC (Fig 2).

When he was 12 days old, the Norwood operation was performed by means of the above technique. Two months after the Norwood operation, the infant underwent a second-stage bilateral bidirectional cavopulmonary shunt.

Discussion. In the left isomeric heart, a single right ventricle with aortic atresia, unobstructed pulmonary artery, and a ductus-dependent systemic circulation is extremely uncommon. ${ }^{3}$ Moreover, a successful Norwood operation for left isomeric heart with aortic atresia has not been reported previously. Among the peculiar morphologic features of the left isomeric heart, pulmonary venous distortion and atrioventricular valve regurgitation increase the risk of the Norwood operation. ${ }^{4}$ On the other hand, because most cases of left isomeric heart have a common atrium or a large atrial septal defect, there is little chance of pulmonary obstructive disease caused by a narrow interatrial communication. Systemic venous anomalies, such as azygos connection, bilateral SVC, or deficiency of IVC, probably do not pose a major risk during the Norwood operation. As shown in the case of patient 2 , the shape of the aortic arch of the left isomeric heart is substantially different from that of hypoplastic left heart syndrome with normal situs.

During the Norwood operation for the isomeric heart with peculiar arterial anomalies, the helical CT images are extremely useful for optimal 3-D orientation of the reconstructed neoaorta. Compared with the images obtained by means of conventional echocardiography or angiography, 3-
D helical CT images allow precise determination of the shape and spatial relation of the great arteries from optional angles. This innovative technique can be adapted, even for neonates and infants with various serious arterial or venous anomalies. ${ }^{2,5}$

Received for publication Oct 10, 2000; accepted for publication Oct 20, 2000.

Address for reprints: Masaaki Yamagishi, MD, Department of Pediatric Cardiovascular Surgery, Children's Research Hospital, Kyoto Prefectural University of Medicine, Kawaramachi, Hirokoji, Kamikyo-ku, Kyoto, 602-8566 Japan (E-mail: myama@koto.kpu-m.ac.jp).

\section{REFERENCES}

1. Van Mierop LHS, Gessner IH, Schiebler GL. Asplenia and polysplenia syndrome: In: Bergsma D, editor. Congenital cardiac defects_-recent advances. Baltimore: Williams \& Wilkins; 1972. p. 47-82.

2. Shiraishi I, Kato Y, Todoroki H, Satoh H, Hamaoka K. Differential color imaging technique of helical CT angiography in the diagnosis of total anomalous pulmonary venous drainage. Circulation 2000;101:2017-8.

3. Van Praagh S, Geva T, Friedberg DZ, Oechler H, Colli A, Frigiola A, et al. Aortic outflow obstruction in visceral heterotaxy: a study based on twenty postmortem cases. Am Heart J 1997;133:55869.

4. Bove EL, Lloyd TR. Staged reconstruction for hypoplastic left heart syndrome: contemporary results. Ann Surg 1996;224:38795.

5. Shiraishi I, Yamagishi M, Toiyama K, Iwasaki N, Hamaoka K. Helical CT angiography in obstructed total anomalous pulmonary venous drainage. Ann Thorac Surg. In press. 